\title{
Determinación de condiciones ambientales para la conservación de granos de cacao (Theobroma cacao $L$ ) deshidratado durante el almacenamiento
}

\author{
Determination of environmental conditions for the conservation of \\ dehydrated cocoa beans (Theobroma cacao $L$ ) during storage
}

\section{Determinação de condições ambientais para a conservação de grãos de} cacau desidratados (Theobroma cacao $L$ ) durante o armazenamento

\author{
Saza Coaji José Nicolás ${ }^{1}$ y Jiménez Forero Javier Alexander ${ }^{2}$ \\ ${ }^{1}$ Ingeniero Agroindustrial Universidad de los Llanos y \\ ${ }^{2}$ Ingeniero de Producción Agroindustrial, Docente Universidad de los Llanos \\ jajimenez@unillanos.edu.co
}

Recibido 26 septiembre 2019, Aceptado 12 de marzo 2020

\section{RESUMEN}

El cacao (Theobroma cacao L.) es uno de los cultivos representativos del departamento del Meta (Colombia), cuyos granos son aprovechados en la industria chocolatera. El almacenamiento es un punto de control ya que en él pueden presentarse fenómenos de deterioro que afectan su calidad. Durante este ocurren variaciones de temperatura y humedad relativa que provocan pérdidas en las propiedades fisicoquímicas y organolépticas de los granos a causa de su capacidad higroscópica, facilitando el crecimiento de hongos. Por tanto, en este trabajo se pretendió determinar condiciones de temperatura y humedad relativa con el fin de buscar prolongar la vida útil de granos de cacao deshidratado durante su periodo de almacenamiento. Para ello se construyeron isotermas de adsorción a temperaturas de 25,30 y $35{ }^{\circ} \mathrm{C}$ para el rango de $\alpha_{w}$ entre 0.146 y 0.891 . Donde se obtuvieron isotermas de tipo II por tener forma de "S" o por ser tipo sigmoidea. Estas se ajustaron a modelos matemáticos comúnmente aplicados en alimentos. El ajuste de los modelos se evaluó con aquel que presentara una raíz del error cuadrado medio (RMSE) más aceptable y un coeficiente de correlación $\left(R^{2}\right)$ cercano a 1. En función de los cuales, se observó que el modelo propuesto por Smith presentó el mejor ajuste de los datos experimentales. Los resultados obtenidos permitieron 
proponer que a condiciones de humedad relativa superior al $51.4 \%$ e igual y/o inferior al $58.9 \%$ y a temperatura de $25^{\circ} \mathrm{C}$, se prolongaría la vida útil de los granos de cacao deshidratados manteniendo estándares de calidad durante el proceso de almacenamiento.

Palabras clave: Isotermas de adsorción, humedad relativa, temperatura, cacao clon FEAR-5.

\section{ABSTRACT}

Cocoa (Theobroma cacao L.) is one of the representative crops of the department of Meta (Colombia), whose grains are used in the chocolate industry. Storage is a point of control since deterioration phenomena can occur that affect its quality. During this period, variations in temperature and relative humidity occur, causing losses in the physicochemical and organoleptic properties of the grains due to their hygroscopic capacity, facilitating the growth of fungi. Therefore, in this work it was tried to determine conditions of temperature and relative humidity in order to seek to prolong the useful life of dehydrated cocoa beans during their storage period. To do this, adsorption isotherms were constructed at temperatures of 25,30 and $35^{\circ} \mathrm{C}$ for the range of aw between 0.146 and 0.891 . Where type II isotherms were obtained by having an "S" shape or by being a sigmoid type. These were adjusted to mathematical models commonly applied in food. The fit of the models was evaluated with that which present a more acceptable mean square error root (RMSE) and a correlation coefficient (R2) close to 1. Based on which, it was observed that the model proposed by Smith presented the best fit of the experimental data. The results obtained allowed us to propose that at conditions of relative humidity greater than $51.4 \%$ and equal to or lower than $58.9 \%$ and at a temperature of $25^{\circ} \mathrm{C}$, the shelf life of dehydrated cocoa beans would be maintained maintaining quality standards during the storage process.

Keywords: Sorption isotherms, water activity, mathematical models, relative humidity, temperature, cocoa FEAR-5 clone.

\section{RESUMO}


Cacau (Theobroma cacao L.) é uma das culturas representativas do departamento de Meta (Colômbia), cujos grãos são utilizados na indústria de chocolate. $O$ armazenamento é um ponto de controle, pois pode apresentar fenômenos de deterioração que afetam sua qualidade. Durante isso, ocorrem variações de temperatura e umidade relativa, causando perdas nas propriedades físico-químicas e organolépticas dos grãos devido à sua capacidade higroscópica, facilitando o crescimento de fungos. Portanto, este trabalho teve como objetivo determinar as condições de temperatura e umidade relativa, buscando prolongar a vida útil dos grãos de cacau desidratados durante o período de armazenamento. Para isso, foram construídas isotermas de adsorção nas temperaturas de 25,30 e $35^{\circ} \mathrm{C}$ para a faixa de aw entre 0,146 e 0,891 . Onde as isotermas do tipo II foram obtidas por ter a forma de "S" ou por ser do tipo sigmóide. Estes foram ajustados a modelos matemáticos comumente aplicados em alimentos. $O$ ajuste dos modelos foi avaliado com o que apresentou o erro quadrático médio (RMSE) mais aceitável e um coeficiente de correlação (R2) próximo a 1. Com base nisso, observou-se que o modelo proposto por Smith apresentava a melhor ajuste dos dados experimentais. Os resultados obtidos permitiram propor que, em condições de umidade relativa superior a $51,4 \%$ e igual e/ou inferior a $58,9 \%$ e a uma temperatura de $25^{\circ} \mathrm{C}$, a vida útil dos grãos de cacau desidratados seria prolongada, mantendo padrões de qualidade durante o processo de armazenamento.

Palavras-chave: Isotermas de adsorção, umidade relativa, temperatura, clone de cacau FEAR-5.

\section{INTRODUCCIÓN}

El cacao (Theobroma cacao $L$ ) es un árbol nativo de Suramérica de las cuencas del Orinoco y Amazonas, el 70.7 \% de la producción mundial de cacao se realiza Costa de Marfil, Ghana e Indonesia; el $20 \%$ es producido por Brasil, Nigeria, Camerún y Ecuador, ocupando Colombia el puesto 11 con el $1.2 \%$ de la producción mundial. Colombia tiene una posición geográfica estratégica en su condición de país tropical, beneficiándose con luminosidad permanente y recursos hídricos durante todo el año. Además, se cuenta definido material genético para su utilización de acuerdo a 
las diferentes zonas agroecológicas del país (Procolombia, 2015). Actualmente en el país las siembras de cacao se están llevando a cabo con materiales conocidos como clones, que corresponden a la combinación de cacao criollo y trinitario realizado por programas de investigación. Dichos clones son altamente resistentes a enfermedades y poseen gran potencial para la producción de cacao fino y de aroma, siendo estos criterios demandados por las industrias chocolateras para satisfacer finalmente al consumidor final (Escobar y Rojas 2001).

Es importante mantener las características organolépticas (color, aroma, sabor) en el grano de cacao, para lo cual se debe realizar un óptimo proceso de poscosecha (fermentación, secado, limpieza, selección, clasificación, empaque y almacenamiento) (Cubillos et al., 2008), con lo cual se podrá obtener un producto de calidad. Sin embargo, se presentan problemas relevantes en las características físicas y organolépticas de los granos de cacao que llegan a incidir en la calidad del producto final. Tales inconvenientes se originan por causales como malas prácticas agrícolas, diversidad de variedades en un mismo cultivo y al manejo inadecuado de poscosecha y con el tiempo el cacao presenta reacciones de deterioro, tales como oxidación de lípidos, degradación de vitaminas, pigmentos y cambios enzimáticos que en gran medida dependen del contenido de humedad y la actividad de agua del producto (Gálvez et al., 2006). La actividad de agua ( $\left.\alpha_{w}\right)$ de un producto es uno de los factores más importantes en la conservación de los alimentos. La posibilidad de que se lleven a cabo diferentes tipos de reacciones químicas, bioquímicas y de crecimiento de microorganismos que puedan afectar la estabilidad del alimento, depende de la actividad de agua. Por tanto, es importante el conocimiento de la reacción de la actividad de agua y el contenido de humedad de equilibrio ( $\mathrm{CHE}$ ) de los materiales alimenticios para predecir los cambios en sus propiedades físicas, químicas y biológicas que ocurren durante la transformación y almacenamiento. Esta relación entre la $\alpha_{w}$ y el CHE a una temperatura constante es denominada isoterma de adsorción, que hace referencia a procesos de adsorción (hidratación o rehidratación) o de desorción (deshidratación) (Zhang et al., 1996). 
La isoterma de adsorción tiene aplicaciones en el análisis y en el diseño de varios procesos como el secado, el mezclado y el envasado de alimentos. Además, sirve para determinar condiciones óptimas de almacenamiento, predicción de vida útil y selección del material de empaque adecuado. La importancia de la determinación de una isoterma de adsorción radica en situaciones como predecir la estabilidad química y física de los alimentos en función del contenido de humedad, observar su influencia en el ambiente sobre el contenido de agua de un alimento envasado, evaluar el tiempo de deshidratación o de hidratación de un producto, entre otros. Pero para correlacionar el contenido de humedad de equilibrio con la actividad de agua de un alimento, existen varias ecuaciones empíricas y semi-empíricas propuestas donde son usadas para realizar el mejor ajuste de correlación. Teniendo un amplio uso en alimentos al tratar sobre sus propiedades físicas (Moreira et al., 2008).

Cabe mencionar que el almacenamiento de los granos de cacao deshidratado es un punto crítico de control ya que en él pueden ocurrir fenómenos de deterioro que afectan su calidad. Durante éste se presentan variaciones de temperatura y humedad relativa que inducen al grano a absorber humedad (capacidad higroscópica) superando el 7 u 8 \%, facilitando la proliferación de hongos y con ello pérdidas en las propiedades fisicoquímicas y organolépticas. Por tanto, el tiempo máximo de almacenamiento es de dos meses aproximadamente. Una vez trascurrido este período, los granos empiezan a deteriorarse y como consecuencia posterior, los agricultores se ven afectados en el precio final de venta a las industrias chocolateras al momento de comercializar su producto (Cubillos et al., 2008).

El proceso de beneficio debe acatar los principios básicos para la conservación de los alimentos y para el caso del cacao, este comprende las operaciones de cosecha, quiebra, fermentación, secado, limpieza y selección, clasificación, empaque y almacenamiento, con la finalidad de obtener un grano de alta calidad. La cosecha se realiza cuando se observa en la mazorca cambios de pigmentación: de verde pasa al amarillo o al rojo y otros similares pasan al amarillo anaranjado. Lo que se considera que el mismo se encuentra en estado óptimo de madurez. En los períodos 
"picos" de cosecha, la recolección se debe realizar semanalmente. En cambio, las temporadas de menor producción se realizan cada dos o tres semanas (Murrieta y Palma, 2018).

Para no obtener resultados desfavorables en cuanto a la calidad de los granos, se recomienda no recolectar frutos verdes o verde amarillentos debido a que sus granos aún están duros y su mucílago no se ha terminado de formar. Lo que ocasionaría una deficiencia en el proceso de fermentación dado a que no se desarrollarían efectivamente cambios en propiedades fisicoquímicas y organolépticas del grano. También, el no dejar sobremadurar las mazorcas ya que propiciaría la germinación de los granos, corriendo el riesgo de que proliferen hongos (fungosas) y con ello, la formación de enfermedades. Otro aspecto importante es la quiebra que consiste en partir la mazorca por la mitad, para luego con ayuda de los dedos, retirar los granos dejando únicamente la placenta incrustada a la mazorca. Posteriormente, se eliminan pedazos de corteza, hojas, mezclados con los granos y estos deben fermentarse antes de 24 horas (FCC, 2015).

La fermentación es el proceso que realiza cambios bioquímicos en el interior de los granos de cacao y con ayuda de microorganismos, permite el desarrollo de propiedades organolépticas del grano (sabor y aroma). La fermentación consiste básicamente en juntar los granos durante 5 a 7 días para descomponer el mucílago (pulpa blanca que envuelve a los granos), causar la muerte del embrión e iniciar la formación de los compuestos precursores del sabor a chocolate (Cardona 2016).

Los microorganismos (levaduras, bacterias ácido lácticas y bacterias ácido acéticas), que favorecen el proceso de fermentación, inician en condiciones anaeróbicas (sin presencia de oxígeno) y finalizan en condiciones aeróbicas (en presencia de oxígeno), formando alcohol, ácido láctico y ácido acético que permeabilizan la membrana que cubre los granos y son participes en la muerte del embrión, propician la disolución y difusión de alcaloides (teobromina y cafeína), y pigmentos (antocianinas) que son responsables de la formación del sabor amargo en el producto terminado (Schwan y Wheals, 2004). 
Después de la fermentación, los granos de cacao se deben deshidratar para reducir la humedad al 7-8 \% y continuar con reacciones bioquímicas faltantes que finalmente producirán los precursores del sabor. Si este porcentaje de humedad llegase a estar por encima de este rango, los granos son susceptibles a enmohecerse (presencia de hongos), causando deterioro en su calidad. De igual forma, el porcentaje de humedad no debe estar por debajo de este rango puesto que granos serían frágiles y quebradizos, lo que ocasionaría rechazo por no cumplir con criterios de calidad. También se puede realizar el secado natural, sobre plataforma de madera, expuestas a la luz del sol durante 3 a 9 días). Se recomienda para el primer día del proceso, voltear los granos a una baja frecuencia y en los días posteriores, aumentarla. La mejor señal de que este proceso ha culminado, es tomar un puñado de granos en horas de la mañana y sentir el crujido al apretarlos. Adicionalmente, en el interior de los granos se observa una estructura arrugada de color pardo (De la Cruz et al, 2009).

La temperatura del aire caliente no debe ser mayor a $60^{\circ} \mathrm{C}$, de lo contrario, puede provocar la inactividad de las reacciones enzimáticas, siendo tales reacciones una de las piezas claves para el desarrollo de precursores del sabor y aroma del chocolate. Adicionalmente, se van formando granos frágiles y quebradizos. Cuando se utiliza secadores, es importante mantener una temperatura de 55 a $60^{\circ} \mathrm{C}$ y así mismo, el tiempo de secado requiere entre 30 a 34 horas (Rahman 2009).

Después del secado, se someten los granos de cacao deshidratados a una minuciosa limpieza y selección, utilizando tamices y ventiladores, los granos se separan por calidad siendo los mejores los que pesan más de un gramo. Luego de este proceso los granos, se empacan en sacos de fique o yute que estén en perfecto estado, siendo su peso neto de $62.5 \mathrm{~kg}$ o sea 16 sacos equivalen a una tonelada métrica. Para su almacenamiento los sacos con los granos se colocan sobre estibas de madera para evitar contacto con el suelo y las paredes. Cada saco debe brindar información del lote como: el productor, tipo de cacao, proceso de fermentación, secado y empaque, con el objetivo de mantener la trazabilidad en los procesos de 
certificación y calidad. El tiempo de almacenamiento es máximo a dos meses antes de que inicie su proceso de deterioro (Tinoco y Ospina 2010).

Para satisfacer las necesidades del comprador, los granos de cacao deshidratados deben cumplir con criterios de calidad, lo que implica un adecuado fermentado y deshidratado ( 7 a $8 \%$ de humedad), libre de olores y de cuerpos extraños y el peso de cada grano no debe ser inferior a 1 gramo. En Colombia la calidad del grano de cacao se rige por la Norma Técnica Colombiana 1252 del ICONTEC 2003, donde se especifican los criterios de calidad de acuerdo con los estándares internacionales. También se especifican los parámetros físicos y químicos aceptados (humedad, grasa y $\mathrm{pH}$ ), el índice de grano que permite determinar su peso promedio, el índice de mazorca o número de mazorcas que se necesitan para obtener $1 \mathrm{~kg}$ de cacao deshidratado (INCONTEC, 2003).

La actividad de agua $\left(\alpha_{w}\right)$ es la herramienta más usada para relacionar las propiedades de un alimento y el contenido de agua, puesto que este factor influye en cambios enzimáticos, reacciones de oxidación de lípidos, degradación de pigmentos y vitaminas, siendo una propiedad intrínseca que se relaciona con el contenido de humedad a través de las isotermas de adsorción y de sorción. El valor de la actividad de agua refleja la cantidad de agua disponible metabólicamente para que un microorganismo se desarrolle en un alimento (Vega y Lara 2006).

Según Labuza et al., (1976), la actividad acuosa se define como la razón de la presión parcial de vapor del agua ( $\mathrm{Pw}$ ) de un alimento sobre la presión de vapor del agua pura $\left(\mathrm{P}_{0}\right)$ a una temperatura dada expresándose entre 0 y 1 . Donde el alimento más estable a cambios que ocurren como consecuencia del almacenamiento es aquel con el valor de actividad acuosa más bajo. La definición de $\alpha_{w}$ (Ecuación 1) tiene su fundamento en el equilibrio asumido entre el alimento y su entorno gas, por el cual sus valores deben ser iguales en ambas fases a temperatura $(T)$ y presión $(\mathrm{P})$.

Ecuación 1: $\alpha_{w}=\frac{P w}{P^{\circ} w}=\frac{H R E}{100}$

Donde: 
$\mathrm{Pw}=$ presión de vapor del agua en equilibrio con el alimento

$\mathrm{P}^{\circ} \mathrm{W}=$ presión de vapor de agua pura a la misma temperatura

$\mathrm{HRE}=$ humedad relativa en equilibrio

La isoterma de sorción se define como la relación entre la actividad de agua y el contenido de humedad de un material en equilibrio a temperatura constante. La cual se obtiene cuando el proceso de equilibrio inicia a partir de una muestra húmeda o seca, permitiendo equilibrarse con la humedad relativa de la atmósfera que la rodea, y finalmente la muestra gana o pierde humedad. Reflejando así, la forma como el agua se liga al sistema (Sajad y Pradyuman, 2016).

Este trabajo se pretende determinar las condiciones de temperatura y humedad relativa con el fin de buscar prolongar la vida útil de granos de cacao deshidratado durante su periodo de almacenamiento a través de la construcción de las isotermas desorción a diferentes condiciones de almacenamiento mencionadas (temperatura y humedad relativa), para conocer el contenido de humedad de equilibrio del grano rehidratado, determinar su variación de actividad de agua. Esto con el fin de disminuir la velocidad de deterioro y formular alternativas para prolongar la vida útil del grano de cacao deshidratado durante el periodo de almacenamiento, manteniendo estándares de calidad en cualquier época del año y ofrecer al agricultor la oportunidad de acceder a un mejor precio en el mercado nacional e internacional.

\section{METODOLOGÍA}

\section{Secuencia Experimental}

La secuencia experimental para la determinación de condiciones de temperatura y humedad relativa durante el almacenamiento de granos de cacao deshidratado mediante la técnica gravimétrica realizada por método estático (Figura 1), siendo las de uso más frecuente cuando se trata de construir la isoterma de un determinado producto (Staudt et al., 2013). 


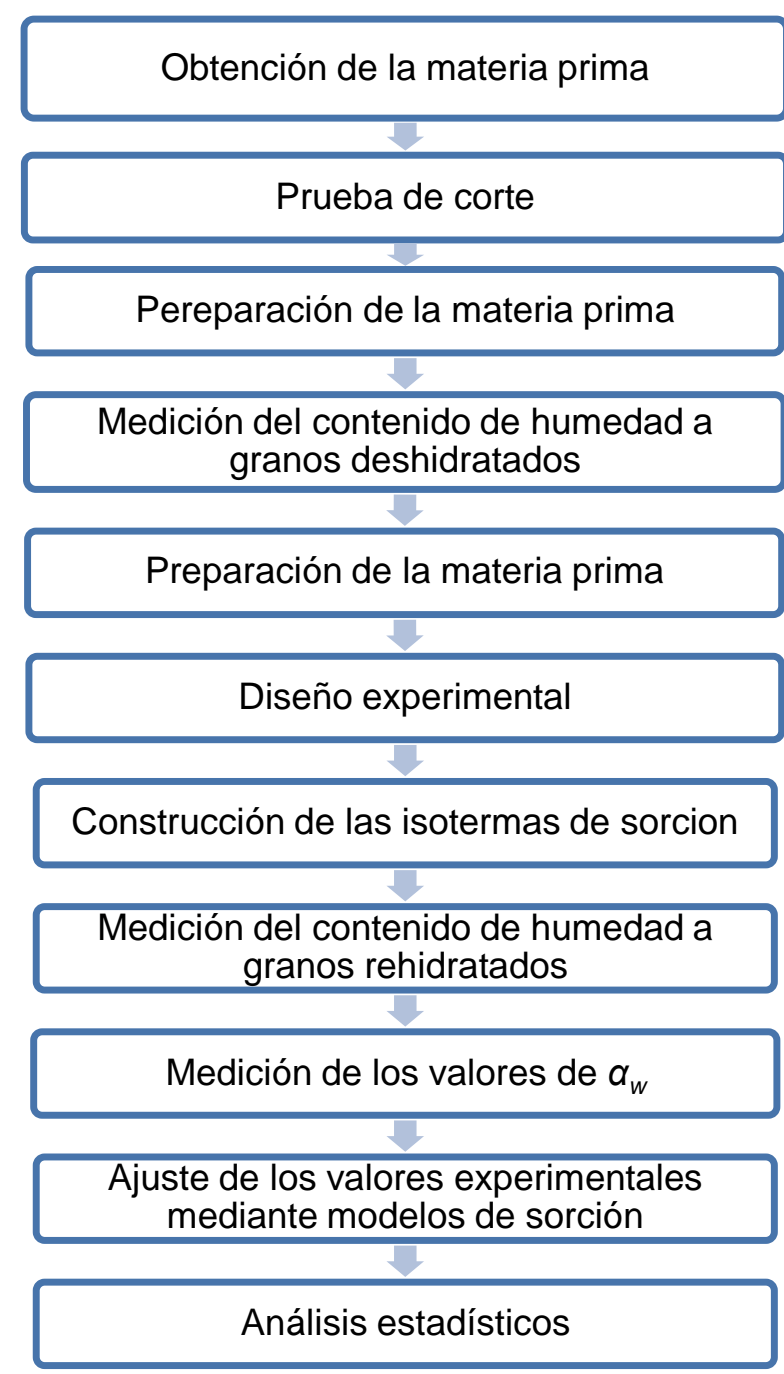

Figura 1. Secuencia experimental según Staudt et al., (2013)

\section{Preparación materia prima utilizada}

Este experimento se realizó en el Laboratorio de Bioprocesos del Programa de Ingeniería Agroindustrial situado en la Universidad de los Llanos, vereda Barcelona en Villavicencio-Meta. Se obtuvo $1 \mathrm{~kg}$ de granos de cacao fermentados (clon FEAR 5) provenientes de una finca ubicada en el municipio de Guamal-Meta. A este material se le identificaron las características físico-organolépticas de un óptimo grano fermentado: color pardo rojizo (externo), muerte del embrión, hinchazón y olor característico de la fermentación (agradable) (Leon-Roque et al., 2016). Además, se tomó una muestra para realizar la prueba de corte. Con el propósito de verificar 
la calidad del grano de cacao fermentado para la ejecución del experimento. Los granos fermentados fueron transportados en cabinas de poliestireno expandido (EPS) refrigeradas a $4 \pm 2^{\circ} \mathrm{C}$ para evitar actividades biológicas y microbiológicas indeseadas.

Se tomaron cinco granos de la materia prima para realizar en cada uno un corte longitudinal con ayuda de un cuchillo de acero inoxidable previamente limpio y desinfectado con hipoclorito de sodio (2 ppm). Finalmente, por observación directa se buscó en el interior de los granos una coloración pardo rojiza con escurrimiento de líquido color vino tinto (Peláez et al., 2016). La materia prima se secó en horno marca Oven modelo ON-01E con recirculación de aire a $60 \pm 2{ }^{\circ} \mathrm{C}$ por un tiempo de 34 a 40 horas, hasta alcanzar una humedad de $7.5 \pm 0.5 \%$ (Valadez et al., 2017).

\section{Determinación del contenido de humedad}

Para determinar el contenido de humedad en el grano deshidratado se empleó el método de A.O.A.C. № 931.04 (2000). Consiste en colocar una caja Petri (9 cm de diámetro) junto con la tapa durante 2 horas en el horno marca Oven modelo ON$01 \mathrm{E}$ con recirculación de aire a $103 \pm 2^{\circ} \mathrm{C}$ hasta secarse completamente. Posteriormente, con la ayuda de pinzas será trasladada (tapada) a un recipiente hermético durante 40 minutos (permitiendo enfriarse) y se pesará en la balanza de precisión marca Kern (m1). Luego se pesarán $5 \mathrm{~g}$ de granos fermentados (m2) previamente homogeneizados en la caja Petri y junto con la tapa se introducirá en el horno a $103 \pm 2^{\circ} \mathrm{C}$ por un tiempo de 6 horas. Trascurrido el tiempo, la caja Petri se tapará para ser transferida al recipiente hermético durante 40 minutos permitiendo enfriarse a temperatura ambiente y por último registrar su peso (m3). Las muestras se procesarán por triplicado para la temperatura de secado. El contenido de humedad en la muestra se calcula por diferencia de peso (ecuación 2).

Ecuación 2: \%Humedad $=\frac{m 2-m 3}{m 2-m 1} \times 100$

Siendo:

m1: Masa de la caja Petri tapada (g) 
m2: Masa de la caja Petri tapada con la muestra antes del secado $(\mathrm{g})$

m3: Masa de la caja Petri tapada más la muestra deshidratada (g)

\section{Diseño Experimental}

Se utilizó un diseño factorial completamente aleatorizado para la obtención de los datos experimentales, en el cual se consideran los siguientes factores: actividad de agua a 7 niveles $(0.146,0.383,0.514,0.589,0.771,0.823$ y 0.891$)$ y temperaturas a 3 niveles $\left(25,30\right.$ y $\left.35^{\circ} \mathrm{C}\right)$. A los datos obtenidos se les aplicará un análisis de varianza (ANOVA) a un nivel de significancia del 95\% empleando el programa estadístico IMB SPSS Statistics 23.

\section{Construcción de las isotermas de sorción}

De acuerdo al promedio de temperaturas predominantes durante el almacenamiento de cacao deshidratado, las isotermas de sorción se determinaron a tres temperaturas de trabajo $\left(25,30\right.$ y $\left.35^{\circ} \mathrm{C}\right)$. Para ello, se colocaron $2 \mathrm{~g}$ de muestra (grano deshidratado) sobre un trípode de acrílico y se introdujeron en recipientes cerrados herméticamente (Figura 2) que contienen soluciones de sal saturadas: Cloruro de Litio ( $\mathrm{LiCl})$, Cloruro de Magnesio $\left(\mathrm{MgCl}_{2}\right)$, Carbonato de Potasio $\left(\mathrm{K}_{2} \mathrm{CO}_{3}\right)$, Nitrato de Magnesio $\left(\mathrm{Mg}\left(\mathrm{NO}_{3}\right)_{2}\right)$, Cloruro de Sodio $(\mathrm{NaCl})$, Cloruro de Potasio $(\mathrm{KCl})$ y Cloruro de Bario $\left(\mathrm{BaCl}_{2}\right)$. Estas fueron preparadas de acuerdo a lo descrito por Spiess, W. y Wolf, W (Tabla 1). Las cuales cubren un rango de actividad acuosa entre 0.146 y 0.891 (Tabla 2) (Rahman, 2008). Posteriormente, los recipientes se llevaron a las temperaturas de trabajo hasta garantizar el equilibrio en el medio. Las muestras se procesaron por triplicado para cada temperatura y para cada solución saturada (Wani y Kumar, 2016). A los recipientes que contienen soluciones de $\mathrm{NaCl}, \mathrm{KCl}$ y $\mathrm{BaCl}_{2}$, se les incorporó $5 \mathrm{~g}$ de Timol contenida en un recipiente de plástico, con el fin de evitar el crecimiento microbiano dado a que el $a_{w}$ de estas soluciones es superior a 0.75 . Este se ubicó sobre el trípode para que no tuviese contacto directo con la solución salina (Muzaffar y Kumar, 2016).

Se utilizó el método gravimétrico estático para el estudio de sorción de granos de cacao deshidratado. El cual implica el uso de soluciones salinas saturadas para 
mantener una humedad relativa en equilibrio a temperatura constante. Para ello, se colocaron aproximadamente $2 \mathrm{~g}$ de muestra (grano deshidratado con contenido de humedad de 7 a $8 \%$ ) en un recipiente de plástico sobre un trípode de material acrílico (por triplicado).

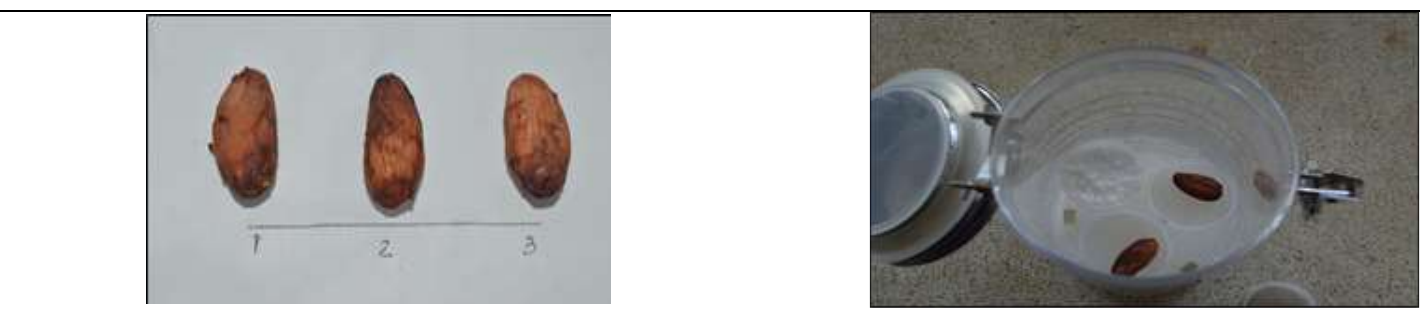

Figura 2. Construcción de isotermas de adsorción para granos de cacao

Tabla 1. Actividades de agua de soluciones de sal seleccionadas

\begin{tabular}{|c|c|c|c|c|c|}
\hline \multirow{2}{*}{ Sales } & \multicolumn{4}{|c|}{ Actividad de agua } & \multirow{2}{*}{$\begin{array}{c}\alpha_{w} \text { en } \\
\text { Aqualab }\end{array}$} \\
\hline & $20^{\circ} \mathrm{C}$ & $25^{\circ} \mathrm{C}$ & $30^{\circ} \mathrm{C}$ & $40^{\circ} \mathrm{C}$ & \\
\hline Carbonato de Potasio & 0.431 & 0.432 & 0.432 & - & 0.514 \\
\hline Cloruro de Bario & - & - & - & - & 0.891 \\
\hline Cloruro de Litio & 0.113 & 0.113 & 0.113 & 0.112 & 0.146 \\
\hline Cloruro de Magnesio & 0.331 & 0.328 & 0.324 & 0.316 & 0.383 \\
\hline Cloruro de Potasio & 0.851 & 0.843 & 0.836 & 0.823 & 0.823 \\
\hline Cloruro de Sodio & 0.755 & 0.753 & 0.751 & 0.747 & 0.771 \\
\hline Nitrato de Magnesio & 0.544 & 0.529 & 0.514 & 0.484 & 0.589 \\
\hline
\end{tabular}

Fuente: Rahman, (2008).

Tabla 2. Preparación de soluciones de sal saturadas recomendadas a $25^{\circ} \mathrm{C}$

\begin{tabular}{lcccc}
\hline \multicolumn{1}{c}{ Sal } & Nomenclatura & $\begin{array}{c}\text { Humedad } \\
\text { relativa (\%) }\end{array}$ & $\begin{array}{c}\text { Sal } \\
(\mathbf{g})\end{array}$ & Agua (ml) \\
\hline Carbonato de Potasio & $\mathrm{K}_{2} \mathrm{CO}_{3}$ & 43.80 & 200 & 90 \\
Cloruro de Bario & $\mathrm{BaCl}_{2}$ & 90.26 & 250 & 70 \\
Cloruro de Litio & $\mathrm{LiCl}$ & 11.15 & 150 & 85 \\
Cloruro de Magnesio & $\mathrm{MgCl}_{2}$ & 32.73 & 200 & 25 \\
Cloruro de Potasio & $\mathrm{KCl}$ & 84.32 & 200 & 80 \\
Cloruro de Sodio & $\mathrm{NaCl}$ & 75.32 & 200 & 60 \\
Nitrato de Magnesio & $\mathrm{Mg}\left(\mathrm{NO}_{3}\right)_{2}$ & 52.86 & 200 & 30 \\
\hline
\end{tabular}

Fuente: Spiess y Wolf, (1987).

\section{Contenido de humedad en grano rehidratado}

El contenido de humedad de la muestra (grano rehidratado) en cada atmósfera se determinó por el método A.O.A.C. № 931.04 (2000), las muestras se pesaron cada 
dos días y fueron retiradas de los recipientes herméticos hasta evidenciar peso constante (Ecuación 3). Se tiene en cuenta el tiempo de pesaje (inferior a un minuto) para evitar cualquier efecto sobre los resultados. A partir de estos datos se determinó el tiempo al cual cada tratamiento en el grano alcanza su equilibrio de saturación de humedad y se realizaron cálculos de peso ganado de la muestra (Ecuación 4).

Ecuación 3: \%CHE $=\frac{\text { Pmche }- \text { Pms }}{\text { Pmche }} \times 100$

Siendo:

Pmche: Peso de la muestra cuando alcanzó el CHE Pms: Peso de la muestra seca

CHE: Contenido de humedad de equilibrio del grano

Ecuación 4: Peso ganado = Peso final - Peso inicial

Siendo:

Peso final: Masa de la muestra rehidratada

Peso inicial: Masa de la muestra deshidratada

\section{Medición de la actividad de agua $\left(\alpha_{w}\right)$}

Se utilizó un equipo modelo Aquablapre para medir la actividad de agua en los granos rehidratados. La variación de la actividad de agua se determinó a diferentes condiciones de humedad relativa y temperatura. Los datos obtenidos junto a los datos de contenido de humedad en equilibrio, permitieron construir las curvas de sorción: \% humedad (base seca) vs aw (Muzaffar y Kumar, 2016).

\section{Ajuste de los valores mediante modelos matemáticos de adsorción}

Para determinar el mejor ajuste de los valores experimentales del contenido de humedad en equilibrio ( $\mathrm{CHE}$ ), se emplearon dos modelos matemáticos (Tabla 3), proporcionan buena correlación en la determinación de isotermas de sorción de diferentes productos y en la predicción de la actividad de agua en variados tipos de alimentos. Sus parámetros se calcularon mediante una regresión no lineal de mínimos cuadrados empleando el software $R$ versión 3.6.1 y se seleccionó el modelo matemático que presente la raíz del error cuadrado medio (RMSE) más 
aceptable (Ecuación 5) y un coeficiente de correlación lineal $\left(R^{2}\right)$ cercano a 1 Ecuación 6) (Wani, y Kumar, 2016).

Tabla 3. Modelos matemáticos para el ajuste de las isotermas de sorción

$$
C H E=k_{1}-k_{2} * \log \left(1-a_{w}\right)
$$

$\mathrm{k}_{1}$ y k2: Parámetros del modelo que dependen del producto

(Smith)

$$
C H E=K_{1}\left(a_{w}\right)^{n_{1}}+K_{2}\left(a_{w}\right)^{n_{2}}
$$

$\mathrm{CHE}=$ Contenido de humedad en equilibrio

$\mathrm{n}_{1} \mathrm{n}_{2}$ : Constantes para el modelo

$\mathrm{K}_{2}$ : Constante relacionada con el calor de adsorción de la multicapa

$\mathrm{K}_{1}$ : Constante relacionada con el calor de adsorción de la multicapa

(Peleg)

Fuente: Labuza,(1984).

Ecuación 5: RMSE $=\sqrt{\frac{1}{N} * \sum_{i=I}^{N}(M p i-M e i)^{2}}$

Ecuación 6: $R^{2}=\frac{\sum_{i=I}^{N}(\hat{\mathrm{y} i}-\bar{Y})^{2}}{\sum_{i=I}^{N}(y i-\bar{Y})^{2}}$

Siendo:

Me: contenido de humedad de equilibrio experimental.

$\mathrm{Mp}$ : contenido de humedad obtenido del modelo predictivo.

$N=$ número de datos experimentales.

$\hat{y} i=$ contenido de humedad de equilibrio experimental.

$y i=$ contenido de humedad de equilibrio experimental.

$\bar{Y}=$ Promedio del CHE obtenido del modelo predictivo.

\section{RESULTADOS Y DISCUSIÓN}

\section{Características de la materia prima}

A los granos de cacao fermentado (clon FEAR 5), se observó hinchazón, coloración pardo rojizo y muerte del embrión, además, se percibió un olor agradable característico de la fermentación. Posteriormente, se tomó una muestra de cinco granos para realizar la prueba de corte a cada uno, evidenciando en la estructura interna una coloración pardo rojiza con escurrimiento de líquido color vino tinto.

Di Mattia et al., (2013) manifiestan que el proceso de fermentación en granos de cacao representa un paso clave para el desarrollo del aroma y sabor del chocolate. 
Provocando la disminución de la solubilidad de polifenoles, reduciendo el amargor y la astringencia, dando lugar al color típico de los granos bien fermentados. Según Ramos, (2013) la fermentación es una acción combinada y balanceada de ácidos, alcoholes, humedad, $\mathrm{pH}$ y temperatura, conducente a la disminución del sabor amargo y la pérdida de teobromina. La fermentación facilita el proceso de secado y la separación de la testa o cáscara de los cotiledones.

Un óptimo grano de cacao fermentado presentará características como: aroma agradable, sabor ligeramente amargo, color marrón achocolatado en su cáscara y toma un aspecto inflado o hinchado debido a la humedad adquirida y se puede separar el cotiledón de la cáscara con suma facilidad. No obstante, cuando los granos no han sido correctamente fermentados presentan características como sabor amargo o astringente (muy pronunciado), aroma desagradable, el color de la testa es blanco, los granos no se hinchan y la cáscara se encuentra muy adherida al cotiledón (Parra, 2013).

Amoa-Awua, (2016) resalta que la prueba de corte es un procedimiento simple y de uso frecuente, basado en los cambios de color registrados durante la fermentación. Que consiste en cortar los granos a lo largo por la mitad y examinar su color interno utilizando una puntuación basada en granos morados y marrones. Sin embargo, este método no es totalmente cuantitativo y la evaluación del color es muy subjetiva. Cabe señalar que este procedimiento se realizó en tres distintas ocasiones para construir las isotermas de sorción a diferentes temperaturas $\left(25,30\right.$ y $\left.35^{\circ} \mathrm{C}\right)$, tras observaciones a las superficies externas e internas de las muestras tomadas y a discusiones encontradas en estudios de varios autores mencionados, se concluye que la materia prima fue adecuadamente fermentada y en calidad era ideal para la ejecución del experimento.

\section{Análisis de la humedad}

Tras realizar la medición del contenido de humedad en granos deshidratados, se obtuvieron porcentajes entre 7 u $8 \%$ de humedad, siendo este el rango permisible y un criterio de aceptación de calidad aceptable (Tabla 4). Una vez alcanzada la 
humedad requerida en la muestra (granos de cacao deshidratados) para continuar con la construcción del montaje para las isotermas de sorción, se observaron cambios en las propiedades organolépticas y físicas en la muestra, siendo estos cambios notorios el color (granos de color pardo rojizo a color marrón), y el olor (se percibía el olor a chocolate).

Tabla 4. Porcentaje de humedad inicial para la construcción de isotermas de sorción por tres repeticiones $(R)$ para cada temperatura.

\begin{tabular}{lll}
\hline \multicolumn{1}{c}{ Muestras para $25^{\circ} \mathbf{C}$} & \multicolumn{1}{c}{ Muestras para $\mathbf{3 0}{ }^{\circ} \mathbf{C}$} & \multicolumn{1}{c}{ Muestras para $\mathbf{3 5}{ }^{\circ} \mathbf{C}$} \\
\hline $\mathrm{R} 1=7,653$ & $\mathrm{R} 1=7,228$ & $\mathrm{R} 1=7,287 \%$ \\
$\mathrm{R} 2=7,564$ & $\mathrm{R} 2=7,500$ & $\mathrm{R} 2=7,441 \%$ \\
$\mathrm{R} 3=7,362 \%$ & $\mathrm{R} 3=7,347$ & $\mathrm{R} 3=7,742 \%$ \\
\hline
\end{tabular}

Prabhakaranr, (2010) afirma que los granos después de la fermentación se deben secar para reducir su contenido de humedad en $60 \%$, quedando, entre 6 y $8 \%$ y de esta manera prevenir la infestación de moho durante el almacenamiento, permitiendo también que algunos de los cambios químicos que ocurrieron durante la fermentación continúen y mejoren el desarrollo del sabor. Además Afoakwa, (2010) reporta que el proceso de secado inicia las principales reacciones de oxidación del polifenol catalizadas por la polifenol oxidasa, dando lugar a nuevos componentes de sabor y pérdida de integridad de la membrana, lo que induce la formación de color marrón. Esto ayuda a reducir la amargura, la astringencia y también el desarrollo del color marrón en los granos de cacao.

Para determinar si las variables siguieron una distribución normal, se ejecutó la prueba de test de normalidad (Tabla 5), estos valores de significancia fueron inferiores a 0.05 para todos los casos; por lo que se rechaza la hipótesis nula, aceptando la hipótesis alternativa para cada una de las variables de medición establecidas.

La aplicación de la prueba de test de normalidad muestra adicionalmente dos gráficos: Histogramas y Normal Probability Plot. La curva normal demuestra que las no siguen una distribución normal. Cada valor observado se le empareja con su valor esperado, procedente éste último de una distribución normal. Si la muestra es extraída de una población normal, ambos valores se encontrarán en la misma línea 
recta. Por tanto, si el gráfico muestra una relación cercana a una línea recta, entonces se "sugiere" que los datos proceden de una distribución normal.

Tabla 5. Resultados de pruebas de normalidad

\begin{tabular}{lllllll}
\hline & \multicolumn{5}{l}{ Kolmogorov-Smirnova } & \multicolumn{5}{l}{ Shapiro-Wilk } \\
\cline { 2 - 7 } & Estadístico & gl & Sig. & Estadístico & gl & Sig. \\
\hline Peso grano de cacao (g) & 0,057 & 336 & 0,010 & 0,954 & 336 & 0,000 \\
$\begin{array}{l}\text { Ganancia de peso grano } \\
\text { de cacao (g) }\end{array}$ & 0,107 & 336 & 0,000 & 0,925 & 336 & 0,000 \\
$\begin{array}{l}\text { Contenido de Humedad } \\
\text { de equilibrio del grano } \\
\text { de cacao (\%) }\end{array}$ & 0,098 & 336 & 0,000 & 0,950 & 336 & 0,000 \\
\begin{tabular}{l} 
Actividad de agua \\
\hline
\end{tabular} & 0,126 & 336 & 0,000 & 0,948 & 336 & 0,000 \\
\hline
\end{tabular}

Si sig. (p-valor) > 0.05: se acepta la hipótesis nula (la variable sigue distribución normal).

Si sig. (p-valor) < 0.05: se rechaza la hipótesis nula (la variable no sigue distribución normal).

a. Corrección de significación de Lilliefors

El ajuste a la recta no se encuentra en la misma línea recta, por lo que se manifiesta que los datos para cada uno de los casos no siguen una distribución normal. Sin embargo, las interpretaciones de ambas gráficas resultan congruentes con la obtenida de los contrastes de Kolmogorov Smirnov Lilliefors y Shapiro Wilks. Adicionalmente, se realizó el análisis exploratorio de datos para estudiar con mayor precisión la forma y las características de la distribución de las variables de medición ( $\mathrm{CHE}$, peso de grano, peso ganado y $\alpha_{\mathrm{w}}$ ), donde se obtuvieron diferencias significativas en los valores del promedio y la mediana en cada una de las variables de medición. Por lo que se sugiere que las variables no siguen una distribución normal dado a que uno de los comportamientos de seguir es que los valores del promedio, mediana y media sean significativamente iguales. Por tanto, el promedio no representa a las variables de medición, caso contrario a la mediana, pues al notar que las variables a medir no tienen una distribución normal, este parámetro, si representa estas variables. Por lo anterior, no se realiza análisis de varianza, sino pruebas no paramétricas.

La prueba de Kruskal-Wallis permite decidir si puede aceptarse la hipótesis de que $\mathrm{k}$ muestras independientes proceden de la misma población o de poblaciones 
idénticas con la misma mediana. Los resultados as realizar la prueba Kruskal-Wallis, muestran significancias inferiores a 0.05 para tres de las variables de medición lo cual permitió determinar que los tratamientos (soluciones salinas) influyeron significativamente en el CHE, peso ganado y $\alpha_{w}$ del grano.

Adicionalmente, se observó en la Tabla 6, que la variable de agrupación "número de grano" arrojó un valor de significancia de 0.837 (superior a 0.05), lo que indica que el número de granos no influenció en la variación del peso del grano. Motivo por el cual concluye que los granos son iguales.

Tabla 6. Prueba de Kruskall-Wallis a variables de medición establecidas

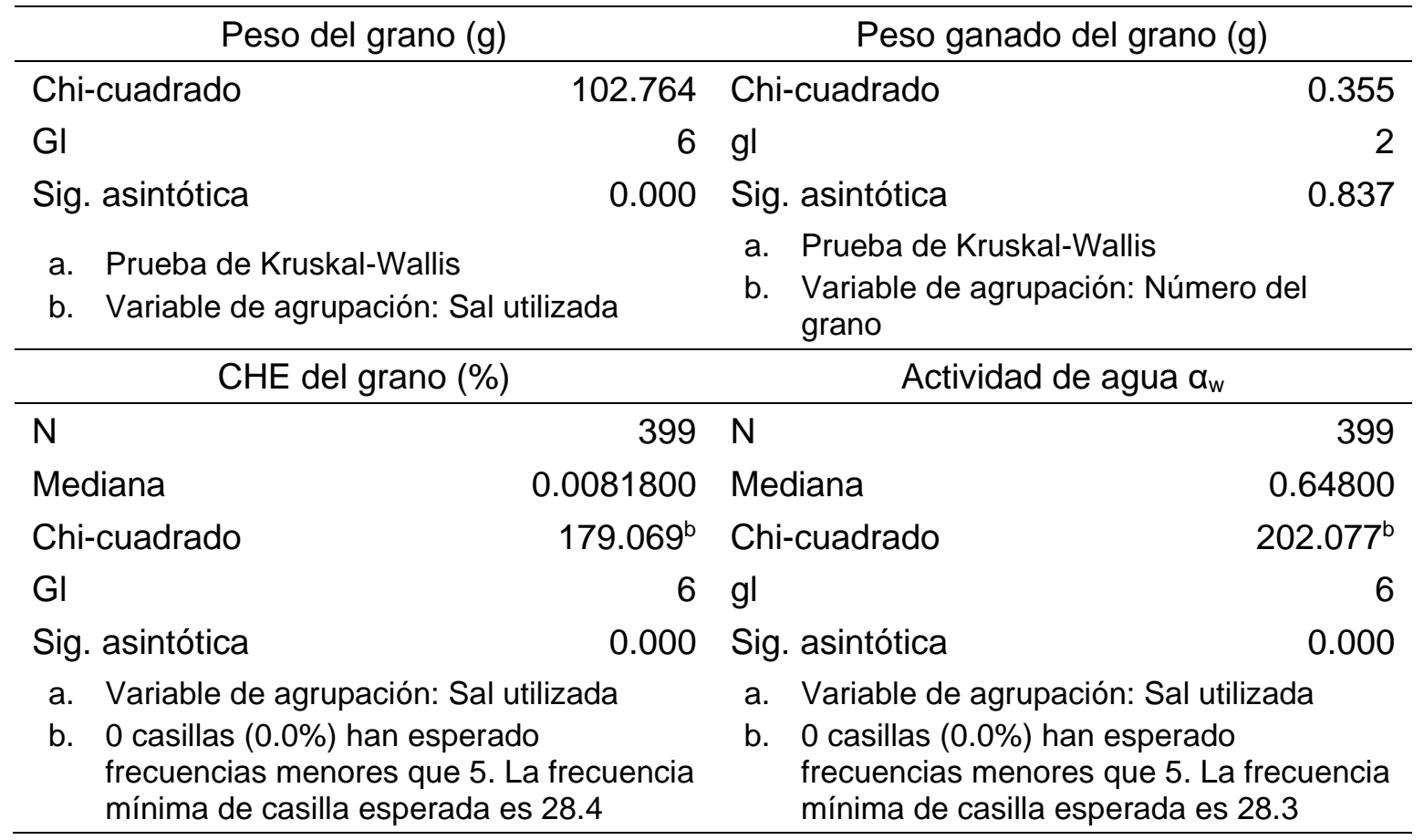

Como la prueba de Kruskal-Wallis no permite identificar cuales tratamientos influyen significativamente en estas variables, entonces para conocer cuáles de los siete tratamientos influyeron en las variables de medición, se realizaron comparaciones pareadas con la prueba de Mann Whitney y así poder determinar las temperaturas que influenciaron significativamente en el CHE, peso ganado y $a_{w}$ del grano para cada tratamiento (Tablas 7, 8 y 9). 
Tabla 7. Peso ganado del grano por temperatura para cada tratamiento (la significancia fue cero)

\begin{tabular}{|c|c|c|c|c|}
\hline Tratamiento & $\begin{array}{c}\text { Estadísticos } \\
\text { Kruskall-Wallis } \\
\mathrm{X}^{2} \\
\end{array}$ & $\begin{array}{c}\text { Temperatura } \\
{ }^{\circ} \mathrm{C}\end{array}$ & $\mathbf{N}$ & $\begin{array}{l}\text { Mediana Peso } \\
\text { ganado del grano }\end{array}$ \\
\hline \multirow{4}{*}{ Cloruro de Litio } & \multirow{3}{*}{38.592} & 25 & 12 & $1.851^{\mathrm{A}}$ \\
\hline & & 30 & 24 & $1.745^{B}$ \\
\hline & & 35 & 21 & $1.619^{C}$ \\
\hline & \multirow{3}{*}{25.951} & 25 & 12 & $1.750^{\mathrm{A}}$ \\
\hline \multirow[t]{2}{*}{ Cloruro de Magnesio } & & 30 & 24 & $1.786^{B}$ \\
\hline & & 35 & 21 & $1.827^{B}$ \\
\hline \multirow{3}{*}{$\begin{array}{c}\text { Carbonato de } \\
\text { Potasio }\end{array}$} & \multirow{3}{*}{33.760} & 25 & 12 & $1.508^{A}$ \\
\hline & & 30 & 24 & $1.819^{B}$ \\
\hline & & 35 & 21 & $1.697^{C}$ \\
\hline \multirow{3}{*}{ Nitrato de Magnesio } & \multirow{3}{*}{40.428} & 25 & 12 & $1.828^{A}$ \\
\hline & & 30 & 24 & $1.916^{B}$ \\
\hline & & 35 & 21 & $1.677^{C}$ \\
\hline \multirow{3}{*}{ Cloruro de Sodio } & \multirow{3}{*}{48.545} & 25 & 12 & $1.582 \mathrm{~A}$ \\
\hline & & 30 & 24 & $1.990^{B}$ \\
\hline & & 35 & 21 & $2.285^{C}$ \\
\hline \multirow{3}{*}{ Cloruro de Potasio } & \multirow{3}{*}{48.438} & 25 & 12 & $1.598^{A}$ \\
\hline & & 30 & 24 & $1.877^{\mathrm{B}}$ \\
\hline & & 35 & 21 & $1.721^{C}$ \\
\hline \multirow{3}{*}{ Cloruro de Bario } & \multirow{3}{*}{16.475} & 25 & 12 & $1.780^{\mathrm{A}}$ \\
\hline & & 30 & 24 & $2.004^{B}$ \\
\hline & & 35 & 21 & $1.900^{B}$ \\
\hline \multirow{3}{*}{ General } & \multirow{3}{*}{81.660} & 25 & 84 & $1.675^{\mathrm{A}}$ \\
\hline & & 30 & 168 & $1.885^{B}$ \\
\hline & & 35 & 147 & $1.756^{c}$ \\
\hline
\end{tabular}

*Comparación pareada entre temperaturas en el tratamiento prueba de Mann Whitney

*Medianas con letras distintas son estadísticamente diferentes

*El promedio no representa el peso ganado del grano, lo representa la mediana

La prueba de Kruskal-Wallis para el peso ganado del grano por temperatura para cada tratamiento dio una significancia de cero (inferiores a 0.05 ) para todos los casos, lo cual determinó que, en los tratamientos de las sales, la temperatura influyó decididamente en el peso ganado del grano la temperatura (Tabla 8). Adicionalmente, en el peso ganado del grano por temperatura para cada tratamiento, se clasificaron en tres grupos ( $\mathrm{A}, \mathrm{B}$ y $\mathrm{C}$ ) las temperaturas que influenciaron significativamente en el peso ganado del grano para cada tratamiento. Esta clasificación por grupos, se estableció dado a que se encontraron temperaturas 
con igual y diferente influencia en el peso ganado del grano para cada tratamiento, (Tabla 8).

Tabla 8. CHE del grano por temperatura para cada tratamiento (la significancia fue cero)

\begin{tabular}{|c|c|c|c|c|}
\hline Tratamiento & $\begin{array}{c}\text { Estadísticos } \\
\text { Kruskall-Wallis } \\
\mathbf{X}^{2}\end{array}$ & $\begin{array}{c}\text { Temperatura } \\
{ }^{\circ} \mathrm{C}\end{array}$ & $\mathbf{N}$ & $\begin{array}{c}\text { Mediana } \\
\text { Humedad en } \\
\text { equilibrio }\end{array}$ \\
\hline \multirow{4}{*}{ Cloruro de Litio } & & 25 & 12 & $-0.029^{A}$ \\
\hline & 11.842 & 30 & 24 & $0.018^{A}$ \\
\hline & & 35 & 21 & $-0.046^{B}$ \\
\hline & & 25 & 12 & $-0.011^{A}$ \\
\hline \multirow[t]{3}{*}{ Cloruro de Magnesio } & 23.564 & 30 & 24 & $-0.030^{B}$ \\
\hline & & 35 & 21 & $-0.039 \mathrm{C}$ \\
\hline & & 25 & 12 & $-0.006^{A}$ \\
\hline \multirow[t]{3}{*}{ Carbonato de Potasio } & 19.881 & 30 & 24 & $-0.004 \mathrm{~A}$ \\
\hline & & 35 & 21 & $-0.306^{B}$ \\
\hline & & 25 & 12 & $0.000^{A}$ \\
\hline \multirow[t]{3}{*}{ Nitrato de Magnesio } & 27.285 & 30 & 24 & $-0.014^{B}$ \\
\hline & & 35 & 21 & $-0.027^{C}$ \\
\hline & & 25 & 12 & $0.031^{A}$ \\
\hline \multirow[t]{3}{*}{ Cloruro de sodio } & 18.445 & 30 & 24 & $0.008 \mathrm{~A}$ \\
\hline & & 35 & 21 & $0.000^{B}$ \\
\hline & & 25 & 12 & $0.044 \mathrm{~A}$ \\
\hline \multirow[t]{3}{*}{ Cloruro de Potasio } & 27.521 & 30 & 24 & $0.027^{\mathrm{B}}$ \\
\hline & & 35 & 21 & $0.018^{c}$ \\
\hline & & 25 & 12 & $0.068^{A}$ \\
\hline \multirow[t]{3}{*}{ Cloruro de Bario } & 20.730 & 30 & 24 & $0.052^{B}$ \\
\hline & & 35 & 21 & $0.053^{B}$ \\
\hline & & 25 & 84 & $0.031^{A}$ \\
\hline \multirow[t]{2}{*}{ General } & 30.748 & 30 & 168 & $0.018^{B}$ \\
\hline & & 35 & 147 & $-0.004 \mathrm{C}$ \\
\hline
\end{tabular}

${ }^{*}$ Comparación pareada entre temperaturas en el tratamiento prueba de Mann Whitney *Medianas con letras distintas son estadísticamente diferentes

${ }^{*}$ El promedio no representa el CHE del grano, lo representa la mediana

Por tanto, para los casos de los tratamientos de Cloruro de Litio, Carbonato de Potasio, Nitrato de Magnesio, Cloruro de Sodio y Cloruro de Potasio. A 25 (grupo A), 30 (grupo B) y $35^{\circ} \mathrm{C}$ (grupo $\mathrm{C}$ ), tuvieron cada una, diferente influencia significativa en el peso del grano en el tratamiento a las demás temperaturas. No obstante, en los tratamientos de Cloruro de Magnesio y Cloruro de Bario, a 30 y 
$35^{\circ} \mathrm{C}$ (grupo B) fueron similares en el peso ganado del grano, pero diferente su influencia a la temperatura de $25^{\circ} \mathrm{C}$ (grupo $\left.\mathrm{A}\right)$.

Tras realizar la prueba Kruskal-Wallis para el CHE del grano por temperatura para cada tratamiento, los valores de significancia fueron inferiores a 0.05 para todos los casos, determinando que, en los tratamientos de las sales, influyó decididamente la temperatura en el CHE del grano (Tabla 9). Adicionalmente, se clasificaron en tres grupos ( $A, B$ y $C$ ) las temperaturas que influenciaron significativamente en el CHE del grano para cada tratamiento. Esta clasificación por grupos, se estableció dado a que se encontraron temperaturas con igual y diferente influencia para cada tratamiento (Tabla 9).

Por tanto, para los casos de los tratamientos de Cloruro de Magnesio, Nitrato de Magnesio y Cloruro de Potasio. Las temperaturas de 25 (grupo A), 30 (grupo B) y $35^{\circ} \mathrm{C}$ (grupo C), tuvieron cada una, diferente influencia en el CHE. Los tratamientos de Cloruro de Litio, Carbonato de Potasio y Cloruro de Sodio, a 25 y $30^{\circ} \mathrm{C}$ (grupo A) fueron semejantes en el CHE del grano, pero se observó diferencia a $35^{\circ} \mathrm{C}$ (grupo B). En el tratamiento de Cloruro de Bario, a 30 y $35^{\circ} \mathrm{C}$ (grupo B) tuvieron la misma influencia el $\mathrm{CHE}$ del grano pero diferente a $25^{\circ} \mathrm{C}$ (grupo $\mathrm{A}$ ).

La prueba Kruskal-Wallis para el $\alpha_{w}$ del grano por temperatura para cada tratamiento fueron inferiores a 0.05 para los casos de los tratamientos de Cloruro de Litio, Nitrato de Magnesio, Cloruro de Sodio y Cloruro de Bario. Esto determinó que, la temperatura influyera en el $\alpha_{w}$ del grano. Sin embargo, dado a los valores de significancia obtenidos y siendo superiores a 0.05 en los casos de los tratamientos de Cloruro de Magnesio, Carbonato de Potasio y Cloruro de Potasio. Se determinó que no influyó la temperatura en el $\alpha_{w}$ del grano. Por tanto, la temperatura no influenció significativamente el $\alpha_{w}$ del grano para los tratamientos de Cloruro de Litio, Nitrato de Magnesio, Cloruro de Sodio y Cloruro de Bario (Tabla 9)

Para de Cloruro de Litio y Nitrato de Magnesio a 25 y $30^{\circ} \mathrm{C}$ (grupo A) tuvieron la misma influencia en el $\alpha_{w}$ del grano, pero fue diferente a $35^{\circ} \mathrm{C}$ (grupo B). Con Cloruro de Bario, a 30 y $35^{\circ} \mathrm{C}$ (grupo B) el comportamiento fue similares para el $\alpha_{w}$ del grano 
y diferentes a $25^{\circ} \mathrm{C}$ (grupo A). Con Cloruro de Sodio a 30 (grupo a A) y $35^{\circ} \mathrm{C}$ (grupo B) observaron diferencias en el $\alpha_{w}, a 5^{\circ} \mathrm{C}$ (grupo $A B$ ) obtuvo la misma influencia que a $30^{\circ} \mathrm{C}$ (grupo A), como también a $35^{\circ} \mathrm{C}$ (grupo B). Finalmente, en los tratamientos con Cloruro de Magnesio, Carbonato de Potasio y Cloruro de Potasio, la temperatura no influenció en el $\alpha_{w}$ del grano, por tanto, se clasificaron en un mismo grupo las temperaturas de 25,30 y $35^{\circ} \mathrm{C}$ (grupo A) para estos tratamientos (Tabla 9).

Tabla 9. Actividad de agua del grano por temperatura para cada tratamiento

\begin{tabular}{|c|c|c|c|c|c|}
\hline \multirow[t]{2}{*}{ Tratamiento } & \multicolumn{2}{|c|}{$\begin{array}{c}\text { Estadísticos Kruskall- } \\
\text { Wallis }\end{array}$} & \multirow[t]{2}{*}{ Temperatura } & \multirow[t]{2}{*}{$\mathbf{N}$} & \multirow{2}{*}{$\begin{array}{c}\text { Mediana } \\
\text { Actividad de } \\
\text { agua }\end{array}$} \\
\hline & $x^{2}$ & Significancia & & & \\
\hline \multirow{3}{*}{ Cloruro de Litio } & & & 25 & 12 & $0.571^{\mathrm{A}}$ \\
\hline & 20.860 & 0.000 & 30 & 24 & $0.553^{A}$ \\
\hline & & & 35 & 21 & $0.467^{\mathrm{B}}$ \\
\hline \multirow{3}{*}{$\begin{array}{l}\text { Cloruro de } \\
\text { Magnesio }\end{array}$} & & & 25 & 12 & 0.599 A \\
\hline & 3.391 & 0.183 & 30 & 24 & $0.531^{A}$ \\
\hline & & & 35 & 21 & $0.530^{A}$ \\
\hline \multirow{3}{*}{$\begin{array}{l}\text { Carbonato de } \\
\text { Potasio }\end{array}$} & & & 25 & 12 & $0.664 \mathrm{~A}$ \\
\hline & 3.461 & 0.177 & 30 & 24 & $0.551^{\mathrm{A}}$ \\
\hline & & & 35 & 21 & $0.553^{A}$ \\
\hline \multirow{3}{*}{$\begin{array}{l}\text { Nitrato de } \\
\text { Magnesio }\end{array}$} & & & 25 & 12 & $0.660^{A}$ \\
\hline & 14.401 & 0.001 & 30 & 24 & $0.610^{A}$ \\
\hline & & & 35 & 21 & 0.559 B \\
\hline \multirow{3}{*}{ Cloruro de sodio } & & & 25 & 12 & $0.726 A B$ \\
\hline & 15.718 & 0.000 & 30 & 24 & $0.731^{\mathrm{A}}$ \\
\hline & & & 35 & 21 & $0.705^{B}$ \\
\hline \multirow{3}{*}{ Cloruro de Potasio } & & & 25 & 12 & $0.771^{\mathrm{A}}$ \\
\hline & 0.851 & 0.653 & 30 & 24 & $0.780^{A}$ \\
\hline & & & 35 & 21 & $0.788^{A}$ \\
\hline \multirow{3}{*}{ Cloruro de Bario } & & & 25 & 12 & $0.825^{A}$ \\
\hline & 9.879 & 0.007 & 30 & 24 & $0.856^{B}$ \\
\hline & & & 35 & 21 & $0.871^{\mathrm{B}}$ \\
\hline \multirow{3}{*}{ General } & & & 25 & 84 & $0.663 \mathrm{AB}$ \\
\hline & 6.595 & 0.037 & 30 & 168 & $0.700^{B}$ \\
\hline & & & 35 & 147 & $0.583^{A}$ \\
\hline
\end{tabular}

${ }^{*}$ Comparación pareada entre temperaturas en el tratamiento prueba de Mann Whitney

*Medianas con letras distintas son estadísticamente diferentes

${ }^{*}$ El promedio no representa el $\alpha_{w}$ del grano, lo representa la mediana

Se observa que existe correlación significativa entre el peso ganado del grano y el $\mathrm{CHE}$, dado a que el valor fue 0.002 (inferior a 0.05). Además, se trata de una 
correlación negativa moderada $(r=-0.403)$, siendo este valor negativo y no muy lejano a cero (0). Por tanto, se puede determinar que estas variables están correlacionadas negativamente de manera moderada. Lo que indica que a medida que una de estas variables aumente, disminuirá la otra y viceversa.

Tabla 10. Correlaciones de Pearson de las variables

\begin{tabular}{lcccc}
\hline & & $\begin{array}{c}\text { Peso ganado } \\
\text { del cacao }(\mathbf{g})\end{array}$ & $\begin{array}{c}\text { Humedad de } \\
\text { equilibrio del grano }\end{array}$ & $\begin{array}{c}\text { Actividad } \\
\text { de agua }\end{array}$ \\
\hline $\begin{array}{l}\text { Peso ganado } \\
\text { del cacao }(\mathbf{g})\end{array}$ & Correlación de Pearson & 1 & $-0.403^{* *}$ & $0.362^{* *}$ \\
$\begin{array}{l}\text { Humedad de } \\
\text { equilibrio del } \\
\text { grano }\end{array}$ & Correlación de Pearson & $-0.403^{* *}$ & 0.002 & 0.006 \\
$\begin{array}{c}\text { Actividad de } \\
\text { agua }\end{array}$ & Correlación de Pearson & $0.362^{* *}$ & 1 & $-0.659^{* *}$ \\
\hline
\end{tabular}

${ }^{* *}$ La correlación es significativa en el nivel 0.01 ( 2 colas). $\mathrm{N}=57$

Por otro lado, se evidencia la correlación significativa entre el peso ganado del grano y el $a_{w} 0.006$ que es inferior a 0.05 , además, se trata de una correlación positiva baja $(r=0.362)$, siendo este un valor negativo y cercano del valor de cero $(0)$. Por tanto, se puede determinar que estas variables están correlacionadas positivamente de forma baja. Lo que indica que a medida que unas de estas variables son proporcionales; cuando aumenta o disminuya una, la otra también lo hará. Adicionalmente, la existencia de correlación significativa entre el CHE y el $\alpha_{w}$, fue de 0.000 (inferior a 0.05). Además, se trata de una correlación negativa alta dado a su valor $(r=-0.659)$, siendo este negativo y lejano del valor de cero (0). Por tanto, se puede determinar que estas variables están correlacionadas negativamente de forma alta. Lo que indica que a medida que una de estas variables aumente, disminuirá la otra y viceversa (Tabla 10).

\section{Isotermas de sorción}

Rahman et al., (2008) manifestaron que el método estático es el método más simple y común para medir la actividad de agua en los alimentos. Siendo sus ventajas: la simplicidad, bajo costo, capacidad para manejar muchas muestras simultáneamente y su fácil operación. Ramírez et al., (2014) expresaron que la 
técnica gravimétrica por método estático es de uso más frecuente cuando se trataba de construir la isoterma de un determinado producto. En cuanto a la prevención del crecimiento de microorganismos en soluciones saturadas con elevados niveles de $\alpha_{w}$, Labuza, (1984) reiteró que para niveles de $\alpha_{w}$ superiores a 0.70 se pueden colocar pequeños recipientes con tolueno contenido dentro del recipiente o frasco sellado. Sin embargo, Smith, (1971) expresó que se puede utilizar acetato fenilmercúrico (altamente tóxico) o timol (para productos no grasos) dentro de un soporte especial. Adicionalmente, mencionó que las soluciones de sal se deben preparar con agua destilada fría y reposarse durante una semana en estado cerrado (durante este período de tiempo se debe agitar una vez al día).

A las muestras contenidas en diferentes condiciones de humedad relativa y temperatura, se le realizaron pesadas y mediciones de $\alpha_{w}$ para poder determinar su contenido de humedad en equilibrio y su variación en el $\alpha_{w}$. Este procedimiento se realizó cada 48 horas y una vez evidenciado el equilibrio (muestra con peso constante con diferencia máxima de $0.002 \mathrm{~g}$ ), las muestras fueron retiradas de los recipientes herméticos. Teniendo en cuenta que se realizó un procedimiento experimental por triplicado, se realizó un promedio a los datos para consolidar un único valor (Tabla 11).

Tabla 11. Datos experimentales de las muestras del estudio de sorción

\begin{tabular}{ccccccc}
\hline \multirow{2}{*}{$\begin{array}{c}\text { Actividad } \\
\text { de agua } \\
\left(\boldsymbol{\alpha}_{\mathbf{w}}\right)\end{array}$} & \multicolumn{2}{c}{$25{ }^{\circ} \mathbf{C}$} & \multicolumn{2}{c}{$30^{\circ} \mathbf{C}$} & \multicolumn{2}{c}{$35{ }^{\circ} \mathbf{C}$} \\
\cline { 2 - 7 } & $\begin{array}{c}\text { Peso } \\
\text { ganado }(\mathbf{g})\end{array}$ & $\% \mathrm{CHE}$ & $\begin{array}{c}\text { Peso } \\
\text { ganado }(\mathbf{g})\end{array}$ & $\% \mathrm{CHE}$ & $\begin{array}{c}\text { Peso } \\
\text { ganado }(\mathbf{g})\end{array}$ & $\% \mathbf{C H E}$ \\
\hline 0.146 & $-0.071 \pm 0.002$ & $-3.873 \pm 0.16$ & $-0.075 \pm 0.016$ & $-4.488 \pm 0.098$ & $-0.078 \pm 0.003$ & $-5.060 \pm 0.023$ \\
0.383 & $-0.020 \pm 0.002$ & $-1.190 \pm 0.056$ & $-0.052 \pm 0.013$ & $-2.746 \pm 0.613$ & $-0.068 \pm 0.001$ & $-3.652 \pm 0.038$ \\
0.514 & $-0.012 \pm 0.004$ & $-0.801 \pm 0.271$ & $-0.040 \pm 0.001$ & $-2.317 \pm 0.152$ & $-0.060 \pm 0.001$ & $-3.476 \pm 0.048$ \\
0.589 & $0.001 \pm 0.001$ & $0.054 \pm 0.001$ & $-0.029 \pm 0.003$ & $-1.584 \pm 0.226$ & $-0.049 \pm 0.002$ & $-2.903 \pm 0.006$ \\
0.771 & $0.050 \pm 0.005$ & $3.130 \pm 0.246$ & $0.026 \pm 0.007$ & $1.283 \pm 0.389$ & $0.010 \pm 0.001$ & $0.480 \pm 0.034$ \\
0.823 & $0.066 \pm 0.004$ & $4.127 \pm 0.240$ & $0.051 \pm 0.002$ & $2.665 \pm 0.165$ & $0.030 \pm 0.001$ & $1.712 \pm 0.027$ \\
0.891 & $0.115 \pm 0.003$ & $6.193 \pm 0.076$ & $0.107 \pm 0.028$ & $5.087 \pm 0.149$ & $0.104 \pm 0.009$ & $5.204 \pm 0.106$ \\
\hline
\end{tabular}

$\mathrm{CHE}=$ Contenido de humedad en equilibrio

Finalmente, con estos datos resultantes se construyeron las curvas de sorción a temperaturas de 25,30 y $35^{\circ} \mathrm{C}$ para granos de cacao deshidratado (Figura 3 ) y se 
determinó el tiempo al cual las muestras alcanzan su respectivo CHE. Donde las muestras sometidas a diferentes humedades relativas y a temperaturas constantes de 25,30 y $35^{\circ} \mathrm{C}$, tomaron un tiempo total de 768 horas (32 días) aproximadamente en alcanzar el equilibrio (peso constante).

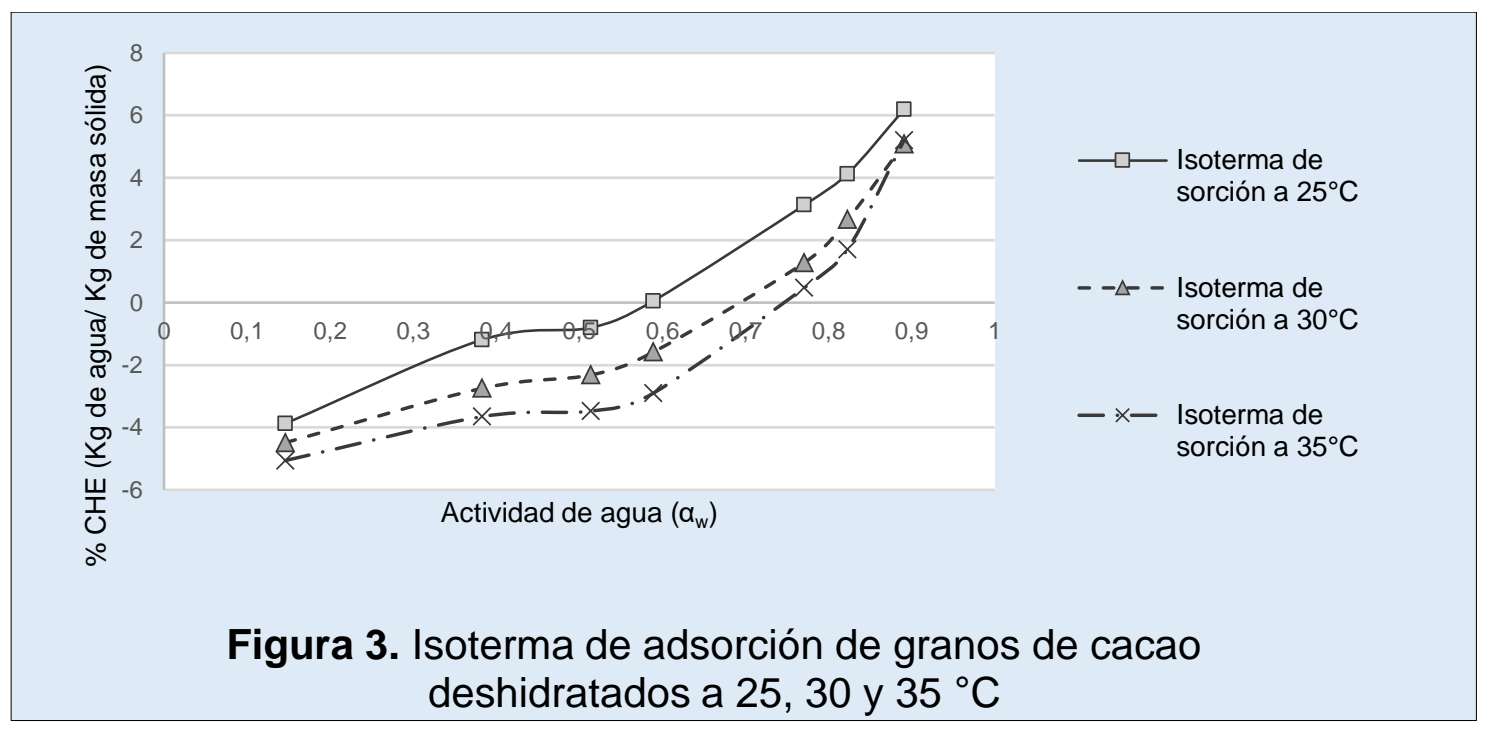

Las muestras que se mantuvieron a $25^{\circ} \mathrm{C}$ tardaron 144 horas (6 días). En cuanto a las muestras que estuvieron a $30^{\circ} \mathrm{C}$ demoraron un periodo de 336 horas (14 días) respectivamente. Por último, las muestras sometidas a $35^{\circ} \mathrm{C}$ tardaron un lapso de 288 horas (12 días) en alcanzar el equilibrio.

En relación al tiempo en que una muestra alcanzó el equilibrio, los autores Khalid y Pradyuman, (2016) realizaron un trabajo de investigación sobre "Isotermas de sorción de humedad y estudio de almacenamiento para la pulpa de tamarindo en polvo secado por pulverización", donde manifestaron que el período de tiempo que requirió la muestra para que alcanzase el equilibrio (peso constante) fue de aproximadamente 3 a 4 semanas. Por otro lado, Yogender y Kamlesh, (2016) presentaron el estudio denominado utilizando la mezcla de sopa instantánea a base de arroz (muestra), alcanzó el contenido de humedad en equilibrio (CHE) en 10 días. Dado a las declaraciones realizadas por los autores mencionados referentes a isotermas de sorción para alimentos, se determinó que los granos de cacao alcanzaron su contenido de humedad en equilibrio entre 1 a 2 semanas. Lo que indica que esta duración está dentro del intervalo de tiempo en el cual un 
determinado producto alimentario alcanza el equilibrio a diferentes condiciones de humedad relativa y temperatura.

Los datos experimentales obtenidos en el estudio de sorción para granos de cacao deshidratados a temperaturas de 25,30 y $35^{\circ} \mathrm{C}$. En ella, se puede observar que son isotermas de tipo II (según los cinco tipos de isotermas establecidas por Van der Waals) por tener forma de "S" o por ser tipo sigmoidea. Debido este comportamiento se insinúa una adsorción física en multicapa. Lo cual significa que la formación de la primera capa ocurre por un rápido ascenso inicial de humedad, siendo esta formación mayor en comparación al restante de las capas. Por tanto, al ir elevando los niveles de actividad de agua se forma la segunda capa de moléculas adsorbidas, seguida una de la otra (Figura 3). Este mismo comportamiento lo reportaron Gálvez et al., (2007) y Ramírez et al., (2014), quienes mencionaron que este tipo de isoterma son frecuentes en verduras y frutas dado a que son productos que adsorben pequeñas cantidades de humedad a niveles bajos de actividad de agua y aumentan considerablemente su adsorción de humedad a altos niveles de actividad de agua.

Cabe recalcar que la actividad de agua $\left(\alpha_{w}\right)$ de un producto se puede medir porque el $\alpha_{w}$ es igual a la humedad relativa del aire en equilibrio con el producto. Por consiguiente, los valores de los niveles de actividad de agua establecidos en el estudio de sorción hacen referencia a la de humedad relativa a la cual los granos de cacao deshidratado no adsorben ni liberan agua al medio en el que se almacenaban.

Prosiguiendo, para este tipo de isotermas se obtuvieron algunos valores negativos en el contenido de humedad de equilibrio de los granos. Considerando que estos cedieron humedad al medio dado a que este medio contenía menor humedad en comparación a los granos de cacao. Estableciendo que a niveles de actividad de agua entre 0.146 y 0.589 (siendo estos valores de $\alpha_{w}$ iguales a los porcentajes de humedad relativa entre 14.6 y 58.9\%), se desarrolló el fenómeno conocido como desorción para cada una de las temperaturas de trabajo. 
Pero a humedades relativas superiores al $58.9 \%\left(\alpha_{w}=0.589\right)$ se evidenció que la humedad de los granos aumentó dado a que el medio en el que se encontraban almacenados contenía mayor humedad en comparación a estos (adsorción). Por tanto, en las isotermas para granos de cacao deshidratado (con 7 a $8 \%$ de humedad) se lograron los fenómenos de adsorción y desorción para cada una de las temperaturas de trabajo establecidas. Las muestras tenían más humedad en comparación al medio que los almacenaba. Por tal motivo, las muestras cedieron humedad al medio obteniéndose ciertos valores negativos en el contenido de humedad en equilibrio para este mismo nivel de actividad de agua.

De lo anterior y detallando las isotermas obtenidas, se estableció que a $35^{\circ} \mathrm{C}$ y a niveles de actividad de agua iguales o inferiores a 0.589 (58.9\% de humedad relativa), los granos cedieron más humedad al medio (mayor presencia del fenómeno de desorción) en comparación a los granos almacenados a 25 y $30^{\circ} \mathrm{C}$. Pero a esta misma temperatura y a niveles de actividad de agua iguales y/o inferiores a 0.711 (71.1\% de humedad relativa), los granos adsorbieron menos humedad del medio (menor presencia del fenómeno de adsorción) en comparación a los granos almacenados a temperaturas de 25 y $30^{\circ} \mathrm{C}$. A excepción del nivel de actividad de agua de 0.891 ( $89.1 \%$ de humedad relativa) contraste a la temperatura de $30^{\circ} \mathrm{C}$, debido a que a estas condiciones los granos almacenados a $35^{\circ} \mathrm{C}$ adsorbieron mayor humedad del medio en comparación a los de $30^{\circ} \mathrm{C}$.

Continuando en orden descendiente referente al fenómeno de desorción, le siguen los granos que estuvieron almacenados a $30^{\circ} \mathrm{C}$ con niveles de actividad de agua iguales o inferiores a 0.589 (58.9\% de humedad relativa). Pero referente al fenómeno de adsorción que se observó en la isoterma de $30^{\circ} \mathrm{C}$ y a niveles de actividad de agua superiores al 0.771 ( $77.1 \%$ de humedad relativa), los granos almacenados bajo estas condiciones adsorbieron más humedad del medio en comparación a los granos almacenados a $35^{\circ} \mathrm{C}$, pero caso contrario ocurrió a un nivel de actividad de agua de 0.891 ( $89.1 \%$ de humedad relativa).

Finalmente, las condiciones donde los granos cedieron menos humedad al medio en comparación a las condiciones de 30 y $35^{\circ} \mathrm{C}$, fueron a temperatura de $25^{\circ} \mathrm{C}$ y a 
niveles de actividad de agua iguales y/o inferiores a 0.514 (51.4\% de humedad relativa). No obstante, a esta misma temperatura, pero a niveles de actividad de agua iguales y/o superiores a 0.589 (58.9\% de humedad relativa), los granos adsorbieron mayor cantidad de humedad del medio en comparación a las otras temperaturas de trabajo.

La ecuación utilizada para las tres temperaturas un $\mathrm{R}^{2}$ en dieron un $\mathrm{R}$ entre 0.907 a 0.960, Considerando ser un modelo útil a la hora de modelar isotermas de sorción para granos de cacao deshidratado. No obstante, se presentaron coeficientes de correlación más cercanos a uno (1) fue el modelo predictivo de Smith, (1971). Reportando un $\mathrm{R}^{2}$ entre 0.941 a 0.988 , determinando que es el que mejor se ajusta a los datos experimentales de granos de cacao deshidratados en el rango de temperaturas evaluado. En las Figuras 4,5 y 6 se presentan las curvas experimentales y modeladas (ajustadas) a 25,30 y $35^{\circ} \mathrm{C}$, respectivamente, utilizando los modelos propuestos, donde se observa de manera gráfica el buen ajuste obtenido con estos modelos.

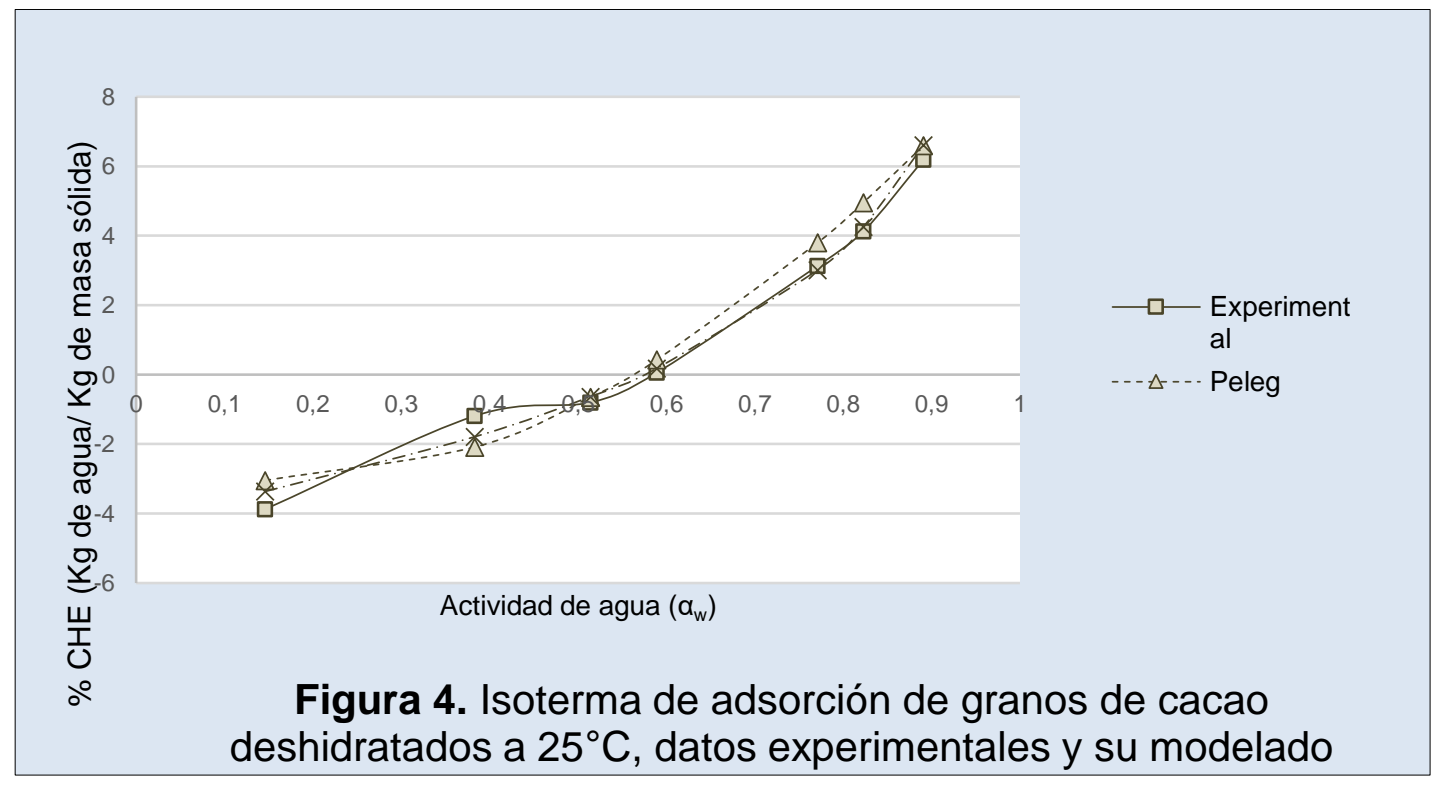

Pudo observarse que las constantes de los modelos propuestos presentaron cambios sin una tendencia clara con base a las temperaturas de trabajo. Demostrando la imposibilidad de utilizar una ecuación generalizada para describir el comportamiento de adsorción en granos de cacao deshidratado. Considerando 
que estas variaciones pudieron deberse a los diferentes supuestos propios de cada modelo. Sin embargo, los modelos empleados han presentado un buen ajuste $\left(R^{2}\right)$ por lo cual cada uno permitió realizar predicciones altamente aproximadas.
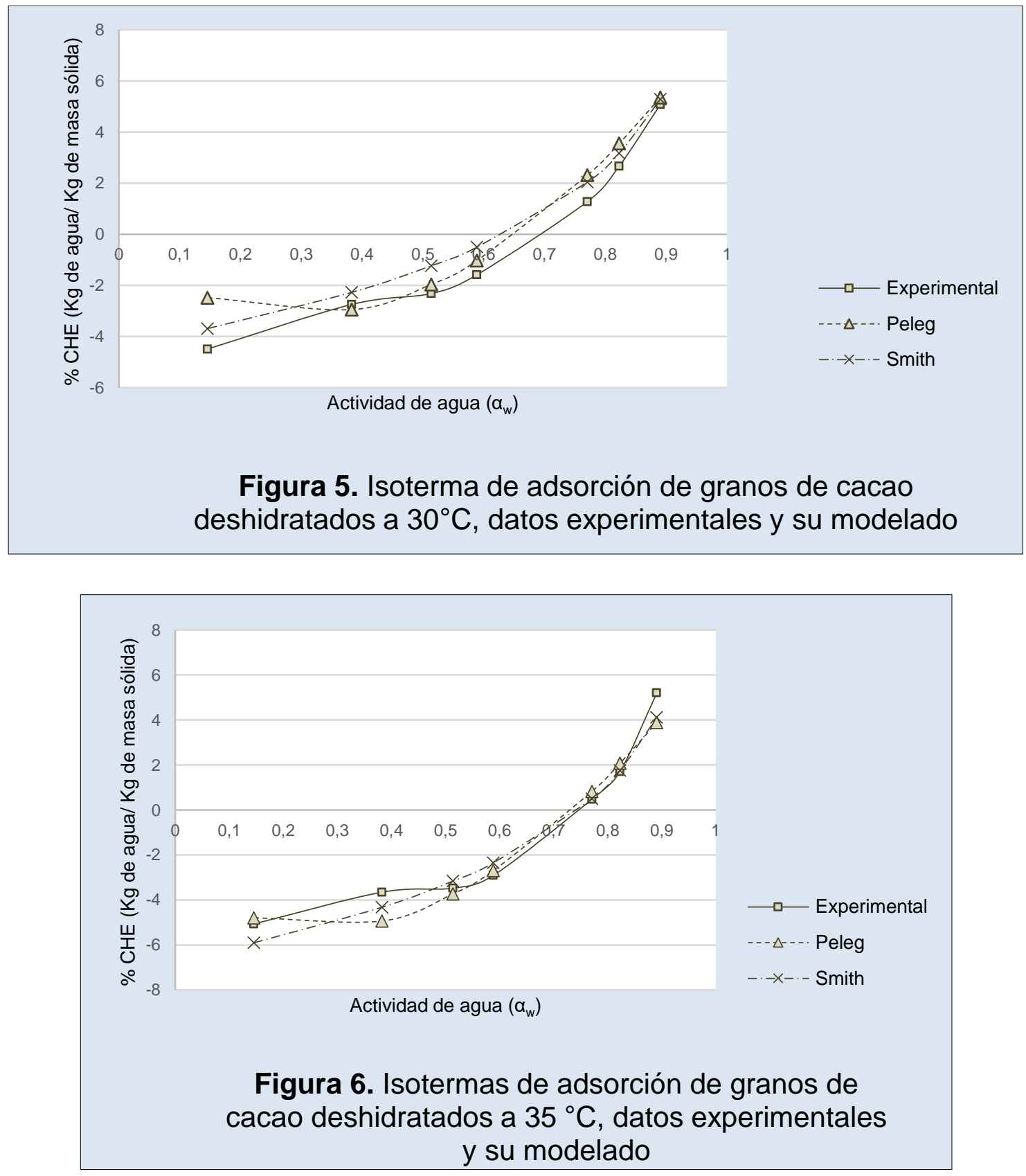

\section{CONCLUSIONES}

De acuerdo a los resultados se puede afirmar que las ecuaciones de Peleg y Smith, modelaron correctamente los datos experimentales para las temperaturas de 
trabajo $\left(25,30\right.$ y $\left.35^{\circ} \mathrm{C}\right)$. Sin embargo, el modelo de Smith presentó el mejor ajuste de los datos experimentales de granos de cacao deshidratados en todo el intervalo de contenido de humedad y actividad de agua considerado en este estudio.

Se pudo observar que las isotermas de adsorción de granos de cacao deshidratado tuvieron forma de "S". Considerándose ser tipo II, lo que insinúa una adsorción física en multicapa, un comportamiento característico de frutas y verduras.

No obstante, a niveles de actividad de agua entre 0.146 y 0.589 , los granos cedieron humedad al medio. Considerando que el medio en el cual los granos estaban almacenados, contenía menor humedad en comparación a estos. Por tanto, se considera la ocurrencia del fenómeno denominado desorción a estos niveles de actividad de agua para cada una de las temperaturas de trabajo.

Teniendo en cuenta que en las isotermas se presenció el fenómeno de desorción, se puede apreciar, además, que al aumentar el nivel de actividad de agua se tiene como efecto el incremento en el contenido de humedad de equilibrio en los granos a temperatura constante. Considerando la tasa de desorción más alta al inicio del estudio de sorción y conforme, va disminuyendo constantemente. Dando inicio a la tasa de adsorción hasta el punto en llegar a la humedad de equilibrio con respecto a las condiciones del medio en el que se encuentran almacenados los granos.

Con base al comportamiento de las isotermas de granos de cacao deshidratados, se expone que la temperatura influyó de forma inversa sobre el contenido de humedad en equilibrio. Lo cual indica que, a un mismo nivel de actividad de agua, el contenido de humedad en equilibrio en los granos de cacao deshidratado será mayor a una baja temperatura y viceversa.

De acuerdo a los resultados obtenidos en esta investigación, se concluye que a condiciones de humedad relativa superior al $51.4 \%$ e igual $\mathrm{y} / \mathrm{o}$ inferior al $58.9 \%$ con temperatura a $25^{\circ} \mathrm{C}$, se prolongaría la vida útil de los granos de cacao deshidratados manteniendo estándares de calidad durante el proceso de almacenamiento. 


\section{REFERENCIAS BIBLIOGRÁFICAS}

1. Afoakwa, E. 2010. Chocolate science and technology. UK: Wiley Blackwell Publishers. 3-82 p.

2. Amoa-Awua, W. 2016. Methods of cocoa fermentation and drying, Prediction of fermentation index of cocoa beans (Theobroma cacao L.) based on color measurement and artificial neural networks. Talanta. 16: 31.

3. AMOA-AWUA, W. 2015. Methods of cocoa fermentation and drying, in R.F. Schwan and G.H. Fleet, Cocoa and Coffee Fermentations, First ed., CRC Press Taylor \& Francis Group, NY, USA. Pag. 71-116 p.

4. Association of Official Analytical Chemist (A.O.A.C.). Official methods of analysis. 931.04. 18th Edition. Gaithersburg, Maryland. USA. 2000.

5. Cardona L. 2016. Influencia del proceso de fermentación sobre las características de calidad del grano de cacao (Theobroma cacao L.). Tesis para Maestría en Ciencia y Tecnología de Alimentos: Universidad Nacional de Colombia, Facultad de Ciencias Agrarias, 99 p. Disponible en: http://bdigital.unal.edu.co/57686/1/43987710.2017.pdf

6. Cortés, F. 2006. Modelamiento del proceso de adsorción y desorción de metanol en un lecho de carbón activado para la aplicación en sistemas de refrigeración solar por adsorción intermitente. Tesis en Maestría de Ingeniería Química, Medellín: Universidad Nacional de Colombia, Facultad de minas, 103 p. Disponible en: https://repositorio.unal.edu.co/bitstream/handle/unal/20177/71226849.2006.pdf?sequence=

7. Cubillos, G, Merizalde G y Correa E. 2008. Manual de beneficio del cacao, Medellín, Colombia 2008. 1-29 p. Disponible en: https://www.chocolates.com.co/wpcontent/uploads/2018/05/manual beneficio cacao.pdf

8. De la Cruz J, Vargas M, Del Angel Coronel O. 2009. Cacao: Operaciones Poscosecha, Organización de las Naciones Unidas para la Alimentación y la Agricultura (FAO). 78 p. Disponible en: http://www.fao.org/3/a-au995s.pdf

9. Di Mattia C, Martuscelli M, Sacchetti G, Scheirlinck I, Beheydt B, Mastrocola D, Pittia P. 2013. Effect of fermentation and drying on procyanidins, antiradical activity and reducing properties of cocoa beans. Food and Bioprocess Technology. 6: 3420-3432.

10. Escobar, J., Rojas, M. 2001. Acuerdo sectorial de competitividad de la cadena del cacao y su agroindustria: Colección de documentos IICA serie Competitividad. $1-40 \mathrm{p}$.

11. Federation of Cocoa Commerce (FCC). 2015. Cacao en grano: Requisitos de calidad de la industria del chocolate y del cacao. 110 p. Disponible en: http://cocoaquality.eu/data/Cacao\%20en\%20Grano\%20Requisitos\%20de\%20Calidad\%20de\%20la\%20Industria\%20Apr\%202016 es.pdf

Gálvez et al. 2006. Isotermas de adsorción en harina de maíz (Zea mays L.) Ciênc. Tecnol. Aliment., Campinas. 26: 821-827.

13. Hansen, C, Del Olmo M, Burri C 1999. Enzyme activities in cocoa beans during fermentation. Journal ofthe Science of Food and Agriculture, 77: 273-281

14. Khalid, M., Pradyuman, K. 2016. Moisture sorption isotherms and storage study of spray dried tamarind pulp. Powder Technology, $291: 322-327$.

15. Labuza, T. 1984. Moisture Sorptions: Practical Aspects of Isotherm Measurement and use. American Association of Cereal Chemists, st. paul, mn. 4.

16. Labuza T, Acott K, Tatinl S, Lee R, flink J, Mccall W. 1976. Water activity determination: A collaborative study of different methods. Journal of Food Science, 41: 910-917. Disponible en: https://onlinelibrary.wiley.com/doi/abs/10.1111/i.1365-2621.1976.tb00751 41 4.x

17. León-Roque N, Abderrahim M, Nuñez-Alejos L, Arribas S, Condezo-Hoyos L, LEÓN, N. et al. 2016. Prediction of fermentation index of cocoa beans (Theobroma cacao L.) based on color measurement and artificial neural networks. Talanta, 161:31-39. Disponible en: https://www.ncbi.nlm.nih.gov/pubmed/27769412

18. Moreira R, Torres R, Chenio F, Vallejo M. 2008. Thermodynamic analysis of experimental sorption isotherms of loquat and quince fruits. J. Foods Eng., 88: 514 521.

https://www.researchgate.net/publication/222921300 Thermodynamic analysis of experimental sorption isotherms of loquat and quince fruits

19. Murrieta E, Palma H. 2018. Manual de buenas prácticas de cosecha postcosecha de cacao a nivel de productor. USAID- Alianza cacao 43 p. Disponible en: https://issuu.com/comunicacionesalianzacacaoperu/docs/manual poscosecha cacao

20. Muzaffar K, Kumar P. 2016. Moisture sorption isotherms and storage study of spray dried tamarind pulp powder. Powder Technology, 29: 322-327. Disponible en: https://kundoc.com/pdf-moisture-sorption-isotherms-and-storage-study-of-spray-dried-tamarind-pulp-powde.html

21. Norma Técnica Colombiana (ICONTEC). NTC 1252. 2003. Cacao en grano, 2003. 12 p. Disponible en: https://pdfslide.net/documents/ntc-1252-cacao-engrano.html

22. Parra, P. 2013. Secado artificial de cacao. Estado de arte. Primer Congreso Salesiano de Ciencia, Tecnología e Innovación para la Sociedad. 211 -238.

23. Peláez P., Contreras D, Guerra S. 2016. Changes in physical and chemical characteristics of fermented cocoa (Theobroma cacao) beans with manual and semi-mechanized transfer, between fermentation boxes. Scientia Agropecuaria, 7: 111-119. Disponible en: https://www.researchgate.net/publication/305368597 Changes in physical and chemical characteristics of fermented cocoa Theobroma cacao beans with manual and semi-mechanized transfer between fermentation boxes

24. Prabhakaran N. 2010. Cocoa (Theobroma cacao L.). In The agronomy and economy of important tree crops of the developing world, pp. 131-180. Elsevier Inc. (Chapter 5).

25. Procolombia. 2015. El cacao colombiano: Oportunidades y retos en el mercado internacional. Bogotá D.C., septiembre 2015, pp 1-31.

26. Rahman, S. (ed.) 2009. Food Properties Handbook. Second Edition. USA. $1088 \mathrm{p}$

27. Rahman, S. y Sablini, S. Water Activity Measurement Methods of Foods. En: Food Properties Handbook. Second Edition: M. Shafiur Rahman. 2008. 1-27 p.

28. Ramírez M, Cruz M; Vizcarra M, Anaya, I. 2014. Determinación de las isotermas de sorción y las propiedades termodinámicas de harina de maíz nixtamalizada. Rev. Mex. Ing. Quím [online]. 13 (1): 165-178.

29. Ramos, G. 2004. La fermentación, el secado y almacenamiento del cacao. Taller Internacional de Calidad Integral de Cacao. Memorias INIAP. Quevedo, Ecuador.

30. Ramos, G. 2013. La fermentación, el secado y almacenamiento del cacao. Taller Internacional de Calidad Integral de Cacao. Memorias INIAP. Quevedo, Ecuador, citado por Parra, P. Secado artificial de cacao. Estado de arte. Primer Congreso Salesiano de Ciencia, Tecnología e Innovación para la Sociedad. $214 \mathrm{p}$.

31. Sajad A, Pradyuman, K. 2016. Moisture sorption isotherms and evaluation of quality changes in extruded snacks during storage. LWT - Food Science and Technology, 74: 448-455

32. Sandoval, A, Barreiro, J. 2002. Water sorption isotherms of non-fermented cocoa beans (Theobroma cacao). Journal of Food Engineering, 51: $119-123$.

33. Sandoval, A, Barreiro, J. 2002. Sorption characteristics of fermented cocoa powder (Theobroma cacao). Rev. Téc. Ing. Unv. Zulia, 25: 49-54.

34. Smith, P.1971. The determination of equilibrium relative humidity or water activity in foods - A Literature Review. The British Food Manufacturing Industries Research Association, England.

35. Spiess, W., Wolf, W.1987. The results of the COST 90 project on water activity. Physical Properties of Food, pp 65-91.

36. Staudt P, Kechinskil C, Tessaro C, Soares R, Cardozo N. 2013. A new method for predicting sorption isotherms at different temperatures using the BET model. Journal of Food Engineering, 114: 139-145. Disponible en: https://www.sciencedirect.com/science/article/pii/S0260877412003500

37. Schwan, R., Wheals, A. 2004. The microbiology of cocoa fermentation and its role in chocolate quality. Critical Reviews in Food Science and Nutrition, 44 (4): 205-221.

38. Tinoco H, Ospina D. 2010. Análisis del proceso de deshidratación de cacao para la disminución del tiempo de secado. Revista ElA, 13: 53-63. Disponible en http://www.scielo.org.co/pdf/eia/n13/n13a05.pdf

39. Vega A, Lara, Lemus M. 2006. Isotermas de adsorción en harina de maíz (Zea mays L.) Ciênc. Tecnol. Aliment., Campinas, 26: 821-827. Disponible en: https://www.redalyc.org/pdf/3959/395940080017.pdf

40. Valadez L, Plazola C, Hernández M, Hernández D, Villarreal F, Necoechea H, A Ortiz A, Ceballo G. 2017. Effects of microwaves, hot air and freeze-drying on the phenolic compounds, antioxidant capacity, enzyme activity and microstructure of cacao pod husks (Theobroma cacao L.). Innovative Food Science and Emerging Technologies, 4: 378-386. Disponible en: https://ipn.elsevierpure.com/es/publications/effects-of-microwaves-hot-air-and-freeze-drying-on-the-

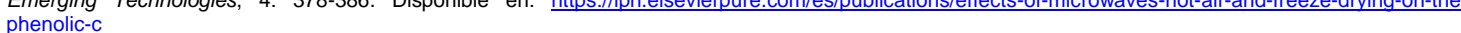
phenolic-c

41. Villamizar, F., Hernández, J. 2011. Determinación de parámetros y simulación matemática del proceso de secado del cacao (Theobroma cacao). Universidad Nacional de Colombia. Facultad de Ingeniería. 1-12 p.

42. Wani, S., Kumar, P. 2016. Moisture sorption isotherms and evaluation of quality changes in extruded snacks during storage. LWT Food Science and Technology, 74: $448-455$ Disponible

https://www.academia.edu/31656076/Moisture sorption isotherms and evaluation of quality changes in extruded snacks during storage

43. Yogender, S., Kamlesh, P. 2015. Sorption isotherms modeling approach of rice-based instant soup mix stored under controlled temperature and humidity. Cogent Food \& Agriculture. 1: 1-11.

44. Zhang, X.; Xie L, De-Xiang G, Wei Z, Ren- L, Pen L. 1996. Desorption Isotherms of Some Vegetables. J.I Scie Food Agric., 70 (3): $303-306$. 